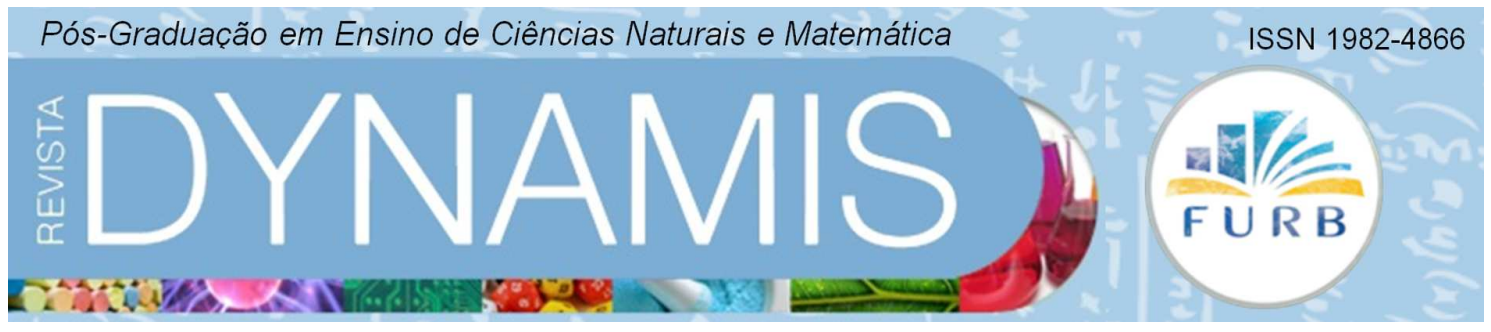

\title{
SABERES DA NATUREZA E ALFABETIZAÇÃO CIENTÍFICA: O COTIDIANO DE UM CENTRO DE EDUCAÇÃO INFANTIL
}

Knowledge of nature and science literacy:

the daily life of an early Childhood Educational Center

\section{Edson Schroeder}

Programa de Pós-graduação em Ensino de Ciências Naturais e Matemática - PPGECIM/FURB Programa de Pós-graduação em Educação - PPGE/FURB

Universidade Regional de Blumenau

ciencia.edson@gmail.com

\section{Aline Rogério}

Universidade Regional de Blumenau

a-rogerio@hotmail.com 


\title{
Resumo
}

Apresentamos uma investigação feita em um Centro de Educação Infantil que consistiu em entrevista com quatro professoras e a coleta de registros no "Livro da Vida" e Projeto Pedagógico. Era objetivo descrever o planejamento das atividades e identificar linguagens utilizadas na abordagem sobre saberes da natureza. Como metodologia de análise utilizamos a Análise do Conteúdo a partir de categorias definidas a priori. O planejamento referencia-se nos saberes cotidianos das crianças, associados à curiosidade e as atividades mobilizam o interesse coletivo, investigação, contato com a natureza e registros. Valoriza-se sensibilização e respeito pela vida por intermédio das diferentes linguagens.

Palavras-Chave: Alfabetização científica. Saberes da natureza. Educação infantil.

\begin{abstract}
We present an investigation made in an Early Childhood Center which consisted of interviews with four teachers, followed by the records contained in the "Book of Life" and in the Teaching Project. The goal was to describe the planning of activities and to identify languages developed in the approach to knowledge of nature. As analysis methodology, we used the Content Analysis from a priori defined categories. The planning reference is in the everyday knowledge of children, when associated with curiosity. The activities were based on research, contact with nature and written and drawn records. We value awareness and respect for life through the use of different languages.
\end{abstract}

Keywords: Scientific Literacy. Knowledge of nature. Childhood education. 


\section{INTRODUÇÃO}

De acordo com o Referencial Curricular Nacional para a Educação Infantil (BRASIL, 1998) é importante ressaltar que, a partir dos anos iniciais de uma criança, acontece importantes processos que envolvem a construção de uma percepção do mundo natural. Esta percepção se dá de forma gradual, conforme as crianças vão desenvolvendo aspectos importantes associados à dimensão psicológica como a curiosidade, a percepção de pertencimento, a motricidade e, sobretudo, diferentes linguagens para, com ela, arquitetar suas explicações sobre o mundo social e natural.

Portanto, nossa atenção voltou-se à educação infantil, com o olhar para o cotidiano de um Centro de Educação Infantil (CEI), com centralidade no ensino dos saberes da natureza e suas contribuições para a alfabetização científica. Partimos do pressuposto de que é função deste espaço educativo viabilizar o acesso das crianças às diferentes culturas, entre elas, a científica, fundamental para a construção da identidade e participação na vida social.

Ao processo de introdução das crianças na cultura científica chamamos alfabetização científica. Esta abrange importantes condições, entre elas, a relação dos professores com os saberes da natureza ensinados, as percepções a respeito dos procedimentos didáticos empregados e o reconhecimento de como as crianças lidam com esses saberes.

O Referencial Curricular Nacional para a Educação Infantil (BRASIL, 1998) aborda diferentes áreas do saber, entre elas, dedica capítulo chamado "Natureza e Sociedade". Neste capítulo apresenta argumentações sobre a importância dos temas relacionados ao mundo natural e suas relações com a sociedade. Já sabemos que são temas pelos quais as crianças demonstram curiosidade e interesse. O capítulo evidencia, também, sobre a importância dos professores valorizarem os conhecimentos cotidianos das crianças, especialmente aqueles relacionados à natureza, uma vez que, embora pequenas, já têm construídas diferentes compreensões, aspecto que caracteriza o que Vigotski (1994) denominou de pensamento empírico. Ainde, conforme o Referencial (BRASIL, 1998, p. 166):

\footnotetext{
No trabalho com os conteúdos referente às Ciências Naturais, por sua vez, algumas instituições limitam-se à transmissão de certas noções relacionadas aos seres vivos e ao corpo humano, desconsiderando o conhecimento e as ideias que as crianças já possuem [...].
}

Como resultante das aprendizagens da criança, incide-se sobre o seu desenvolvimento (VIGOTSKI, 2004), um aspecto do seu funcionamento psicológico, caracterizado pela tomada gradual, não somente da autoconsciência como da consciência de mundo e das distintas formas de vida, seus fenômenos e relações. Ratificamos que o professor, ao valer-se destes conhecimentos, favorecerá a abertura de caminhos para se chegar às compreensões já construídas pelas crianças e sobre elas atuar, não só como orientador, apoiador, mas, sobretudo, como desafiador.

A despeito dos diversos desafios que se apresentam aos professores no seu cotidiano profissional (de ordem estrutural, material, de conhecimento, entre outros) é possível identificar boas práticas no que diz respeito a atributos como a qualidade do trabalho desenvolvido em um CEI, especialmente se olharmos para o ensino dos saberes da natureza. Esta constatação tem por base as inserções do Programa de Extensão "Educação em Ciências 
para o Século XXI" (desenvolvido na Universidade Regional de Blumenau), que promove ações de capacitação a apoio teórico e metodológico de professores. Como exemplo, mencionamos a oferta de cursos de capacitação docente aos profissionais que atuam nos CEIs que acontecem no decorrer do ano, envolvendo professoras e demais profissionais que atuam nestes espaços.

Este movimento possibilitou que entrássemos em contato com diferentes realidades, experiências, percepções, bem como a identificação das dificuldades e anseios dos profissionais que lá atuam. Neste sentido, foi possível perceber que muitas ações voltadas para o ensino dos saberes da natureza ficam restritas ao CEI. Em nosso julgamento, estas ações constituem um rico banco de informações que necessitam ser conhecidas e avaliadas, em seus potenciais pedagógicos, sociais e psicológicos e, possivelmente, desencadeadoras da alfabetização científica. $\mathrm{O}$ que colocamos em evidência são esses potenciais associados às propostas de ensino, já amadurecidas empiricamente, uma vez que foram pensadas e experenciadas pelos professores e suas crianças no dia-a-dia da instituição, com todos os seus desafios e potenciais subjacentes, deste modo, entendemos ser este o principal objeto de estudo: o cotidiano anônimo do ensino dos saberes da natureza para crianças, que acontece nas periferias do nosso município. Portanto, os seguintes objetivos foram definidos para o desenvolvimento da pesquisa:

a) descrever como acontece o planejamento das atividades que envolvem saberes sobre a natureza, pelas professoras do CEI.

b) identificar linguagens desenvolvidas por intermédio das atividades que envolvem os saberes sobre a natureza.

A alfabetização científica, de modo geral, abrange importantes dimensões, entre elas, o processo de formação e capacitação continuada dos professores. Essa formação tem sido um ponto de partida para reflexões com vistas às estratégias de mudanças na perspectiva da construção de sistemas que qualifiquem, cada vez mais, o profissional da educação que atua com crianças.

\section{O ENSINO DOS SABERES DA NATUREZA NA EDUCAÇÃO INFANTIL}

Conforme o Referencial Curricular Nacional para a Educação Infantil (BRASIL, 1998) o trabalho com os conhecimentos provenientes das ciências naturais deve ser orientado para a ampliação das experiências das crianças e para a construção de diferentes conhecimentos acerca do meio social e natural. O documento aborda questões como a pluralidade de fenômenos físicos, biológicos, geográficos, históricos e culturais, bem como a diversidade de explicações e representações sobre o mundo.

A ciência apresenta um modo característico de produção do conhecimento, cuja importância é indiscutível, diferindo de outras formas de explicação e representação do mundo, como as lendas e mitos ou os conhecimentos cotidianos (BRASIL, 1998). Por conseguinte, o ensino de ciências na educação infantil (um eixo denominado "Natureza e Sociedade" deve possibilitar experiências que aproximem às formas de explicação e representação sobre o mundo social e natural. Conforme Harlan e Rivkin (2002, p, 22), "quando o desejo humano de compreender o mundo está organizado de forma criteriosa para coletar, testar e partilhar informações temos o que chamamos ciência".

Quando se possibilita às crianças vivências instigantes, na verdade, estamos influenciando uma importante necessidade humana: a de conhecer melhor o mundo da qual 
fazemos parte. Harlan e Rivkin (2002) asseveram, também, uma condição primordial para este processo: a afetividade, respeitando-se os interesses, a natureza e a necessidade das crianças. Vale ressaltar que, neste contexto, quando tratamos de crianças, a afetividade tem relações intrínsecas com $\mathrm{o}$ ato de conhecer, influenciando diretamente aspectos como a curiosidade, a emoção, além da autoconfiança.

$\mathrm{Na}$ medida em que a criança se desenvolve e sistematiza conhecimentos relativos à ciência, vai reconstruindo diferentes noções que provocam mudanças no seu modo de compreender o mundo (LORENZETTI; DELIZOICOV, 2001). Nesse processo, vão percebendo, de forma gradual, as relações causais, desenvolvem suas capacidades associadas à identificação das propriedades dos objetos e seres vivos, além da percepção dos processos de transformação. Isso ocorre mediante a utilização de diferentes linguagens (pela fala, o desenho, o canto, etc.), denominam e representam o mundo, informando seus sentimentos, desejos e conhecimentos sobre as coisas que observam e vivem (BRASIL, 1998). Nesta fase, a criança encontra-se em um intenso processo de desenvolvimento das suas capacidades intelectuais e um ensino adequadamente organizado contribuirá para a construção de noções muito mais adequadas a respeito dos fenômenos naturais e tecnológicos que fazem parte do seu cotidiano. (ARCE; SILVA; VAROTTO, 2011)

Crianças são muito curiosas e nessa etapa do desenvolvimento é pertinente à utilização do contato direto com os objetos de estudo e também com os livros, o manuseio e a observação, a investigação, os registros, procurando-se valorizar o conhecimento que a criança traz de casa, estimulando, sobretudo, as atitudes científicas (ASTOLFI; PETERFALVI; VÉRIN, 1998). Pretende-se promover o interesse emocional e intelectual da criança, portanto, alguns pontos devem ser considerados nesse processo, como a capacidade de questionamento, além da exploração dos conhecimentos prévios (VIGOTSKI, 2004; 1994). HARLAN E RIVKIN (2002) argumentam que a compreensão de algo supõe uma integração com conhecimentos já existentes e compete aos professores auxiliar as crianças no estabelecimento das relações possíveis:

Auxiliar as crianças a organizarem suas ideias, proporcionando a elas o acesso a palavras comuns relacionadas ao assunto e ampliando seu raciocínio, constitui o papel das pessoas que sabem um pouco mais, como é o caso dos professores. (HARLAN; RIVKIN, 2002, p. 35)

Vigotski destaca, no processo de desenvolvimento da criança, o papel da linguagem e da aprendizagem, atribuindo importância à relação professor-criança durante o processo de ensino. Segundo Vigotski (1994, p. 115):

[...] a aprendizagem não é, em si mesma, desenvolvimento, mas uma correta organização da aprendizagem da criança que conduz ao desenvolvimento mental, ativa todo um grupo de processos de desenvolvimento, e esta ativação não poderia produzir-se sem a aprendizagem. Por isso, a aprendizagem é um momento intrinsecamente necessário e universal para que se desenvolvam na criança essas características humanas não naturais, mas formadas historicamente.

Embora alguns professores receiem em trabalhar os conhecimentos científicos, evidenciamos que sua construção é passível de um processo que situa as crianças como protagonistas centrais. Surpreender-se com as descobertas, de forma compartilhada, traz 
contribuições para a aprendizagem de todos, sobretudo das crianças. (ARCE; SILVA; VAROTTO, 2011)

\section{PROCEDIMENTOS METODOLÓGICOS}

Definimos a investigação como qualitativa, por tratar-se de um conjunto de práticas interpretativas, sobretudo por analisarmos dizeres que expressam compreensões, além de utilizar o banco de dados documental disponível. Tratou-se, também, de uma pesquisa de campo, uma vez que os dados foram coletados nos ambientes naturais onde os sujeitos encontram-se desempenhando suas tarefas cotidianas, com foco no modo de pensar destes sujeitos.

Optamos como cenário de pesquisa, um CEI situado em um bairro de Blumenau, que atende crianças de famílias de classe média e moradoras da região. A instituição tem um trabalho expressivo voltado para o ensino dos saberes da natureza, sinalizando disponibilidade em participar da nossa pesquisa. Obviamente, os encaminhamentos éticos necessários foram efetivados, como a solicitação de autorização à direção e a assinatura do Termo de Consentimento Livre e Esclarecido por todas as profissionais envolvidas na pesquisa.

$\mathrm{Na}$ primeira etapa, quatro professoras participaram da pesquisa (doravante denominadas P1, P2, P3 e P4), concedendo entrevista semiestruturada, gravadas em áudio e posteriormente transcritas e analisadas. A entrevista foi um importante instrumento para nossa pesquisa uma vez que, de acordo com Bauer, Gaskell e Allum (2008, p. 21) captam a "maneira como as pessoas espontaneamente se expressam e falam sobre o que é importante para elas e como elas pensam sobre suas ações e as dos outros". Optamos pelas entrevistas individuais em profundidade. Em nosso caso, as entrevistas tiveram por objetivo compreender aspectos do projeto educativo, com atenção à dimensão conceitual (como definiam os saberes da natureza que desenvolviam com as crianças, como articulavam os conteúdos entre si), à dimensão didática (a definição e a articulação dos recursos e estratégias utilizadas) e à dimensão psicológica (como concebiam a criança e o processo de construção dos conhecimentos).

$\mathrm{Na}$ segunda etapa da pesquisa, utilizamos outras duas fontes de dados: o PPP (Projeto Político Pedagógico), importante documento com informações sobre o CEI e sua concepção relacionada à criança e ao papel da instituição na construção da sua identidade e uma coletânea de documentos produzidos e constituídos por produções das crianças na forma de registros (desenhos, pinturas, colagens), fotografias e registros escritos pelas professoras contendo a descrição detalhada das atividades desenvolvidas. Esta coletânea resulta, anualmente, em um único documento, denominado "Livro da Vida", que se trata de um instrumento fundamental de registros que definem as trajetórias das crianças e suas professoras.

A etapa das análises tratou-se de um importante movimento da pesquisa e teve como seu principal objetivo procurar sentidos e compreensões. Neste sentido, a pesquisa contemplou duas modalidades analíticas e relacionadas à pesquisa qualitativa: a análise do conteúdo e a análise documental. Definimos, a priori, categorias de análise, de acordo com os objetivos da pesquisa, assim definidas:

a) planejamento das atividades que envolvem saberes sobre a natureza.

b) linguagens desenvolvidas por intermédio das atividades que envolvem os saberes sobre a natureza. 
A partir dos conteúdos das respostas, utilizamos, para a efetivação das análises das mensagens, uma metodologia de apreciação conhecida como Análise do Conteúdo (FRANCO, 2005). Esta é utilizada nas pesquisas qualitativas, objetivando produzir inferências acerca de dados verbais e simbólicos, obtidos a partir dos questionamentos e das observações pertinentes à pesquisa. Como ponto de partida da Análise do Conteúdo, tem-se a mensagem oral ou escrita, gestual ou tácita. Ou seja, os sujeitos atribuem um sentido às mensagens verbais ou simbólicas e que estão conectadas às suas condições sociais e culturais.

A Análise Documental (VERGARA, 2010) possibilita a validação das informações obtidas durante a entrevista com as professoras. Além disto, busca identificar informações baseada em fatos, a partir dos documentos, com o foco nas questões de interesse. Como vantagens, destacamos: tratar-se de uma fonte estável e rica, seu baixo custo, além de complementar informações obtidas por intermédio das entrevistas. As informações coletadas foram trianguladas, definida por Vergara (2010, p. 242) como "uma estratégia de pesquisa baseada na utilização de diversos métodos para investigar um mesmo fenômeno". A triangulação, também pode ser percebida tanto como estratégia para o alcance da validade e uma opção para a aquisição de novos conhecimentos.

\section{APRESENTAÇÃO DOS RESULTADOS E ANÁLISES}

\subsection{O CEI PESQUISADO E SUA PROPOSTA}

A pesquisa foi realizada em um CEI localizado em um bairro, distante da área central do município de Blumenau. A Instituição trabalha de segunda à sexta-feira e atende atualmente 90 crianças e 87 famílias de classe média, de acordo com o Projeto Político Pedagógico PPP. (BLUMENAU, 2007)

A partir de 2004, confrontou-se com inúmeros desafios que foram sendo superados na medida em que a instituição formalizava uma identidade própria, na forma de pensar a criança e seu processo de desenvolvimentos, o papel dos professores e demais profissionais envolvidos, além da participação direta da comunidade. Como resultado dos desafios e sua superação, conquistou avanços pedagógicos expressivos, como a complementação e ampliação de projetos, com destaque ao "Livro da Vida", a criação de movimentos culturais, o jornal informativo, a construção da biblioteca entre outros avanços (BLUMENAU, 2007). Um projeto educativo centrado na criança se esboçava, a partir das experiências que caracterizaram o fazer cotidiano dos envolvidos. Por esta razão, o planejamento pedagógico contempla novas lógicas, superando às tradicionais que consideravam, por exemplo, datas comemorativas como ponto de partida para o planejamento, aspecto que algumas vezes, não faz sentido para muitas crianças. Segundo o PPP (BLUMENAU, 2007, p.30), "Nosso papel é outro, de respeitar sim as crenças familiares e cultivar valores que não durem apenas um dia, mas valores em que o respeito e a afetividade pelo outro esteja presente o ano inteiro".

Além do projeto geral que envolve a Instituição como um todo, também são desenvolvidos projetos denominados "projetos de turma". A partir do ano de 2005, o projeto geral é denominado "A criança no mundo das linguagens." Este, está interligado a três eixos: a brincadeira, as interações e as linguagens. Vale ressaltar que a linguagem, segundo as Diretrizes Nacionais da Educação Infantil (BRASIL, 2010), não é considerada como um eixo norteador, porém o CEI a definiu como eixo central de sua proposta curricular. 
Em 2013, o projeto teve como foco de estudo "As culturas escondidas do Médio Vale do Itajaí". Foram distribuídos temas para pesquisa, como dança, artes visuais, poesia e brincadeiras. Os projetos de turma são planejados e desenvolvidos a partir de observações do perfil da turma. Este perfil leva em consideração curiosidades, interesses e atitudes das crianças.

A estrutura interna consiste, além das salas e os banheiros, uma cozinha e refeitório, além da biblioteca. Esta possui um acervo de qualidade, tanto literário quanto musical, totalmente voltado para as crianças. As salas são espaços que estão em constantes mudanças e se transformam com a participação das crianças. A parte externa é rica em elementos naturais: há um amplo bosque com diferentes espécies de plantas e um espaço para horta. O CEI também possui um parque e um galinheiro, construído com a ajuda dos pais.

O grupo funcional era composto por 12 professoras quando a pesquisa aconteceu, em 2013. Sua equipe gestora é formada pela coordenadora pedagógica, além da diretora. A maior parte das professoras possui graduação em pedagogia e coordenadora e diretora são especialistas.

\title{
4.2 O PLANEJAMENTO DAS ATIVIDADES QUE ENVOLVEM SABERES SOBRE A NATUREZA
}

Conforme as Diretrizes Curriculares para a Educação Infantil a criança é:

\begin{abstract}
Sujeito histórico e de direitos que, nas interações, relações e práticas cotidianas que vivencia, constrói sua identidade pessoal e coletiva, brinca, imagina, fantasia, deseja, aprende, observa, experimenta, narra, questiona e constrói sentidos sobre a natureza e a sociedade, produzindo cultura. (BRASIL, 2010, p. 12)
\end{abstract}

Portanto, também é preocupação do professor a procura de propostas centradas nas experiências das crianças a partir de contextos relacionados aos saberes da natureza, uma vez que fazem parte da sua cultura e são fundamentais para o processo de se constituir humano (VIGOTSKI, 1994). Entretanto, asseveramos que o professor necessita respeitar os princípios éticos, políticos e estéticos envolvidos neste processo, preocupação também destacada pelo documento:

\footnotetext{
A educação infantil deve garantir para a criança a construção de novas formas de sociabilidade e de subjetividade comprometidas com a ludicidade, a democracia, a sustentabilidade do planeta e com o rompimento de relações de dominação etária, socioeconômica, étnico-racial, de gênero, regional, linguística e religiosa. (BRASIL, 2010, p. 17)
}

Quando questionadas sobre como planejavam suas atividades envolvendo saberes da natureza, foi possível perceber que as professoras estão atentas para o interesse e necessidades das crianças. A este respeito, P1 [entrevista] menciona que todos os seus planejamentos acontecem a partir de observações que surgem do olhar curioso da criança: "a criança é que sempre vai trazer para gente o que elas querem pesquisar." P1, acrescenta: "Nós, desde o 
começo do ano, [...] observamos muito eles... e o projeto sempre inicia de uma observação deles [...]. Entretanto, argumenta que os projetos acabam se entrelaçando, na maioria das vezes, com os saberes da natureza, pois o espaço circundante contribui para as atividades que contemplam a fauna e a flora, que acaba influenciando no cotidiano da instituição.

Para P2 o planejamento não acontece de forma fragmentada e como a sua turma ainda não domina a linguagem falada, como expressão, "tudo acontece através de enigmas" [entrevista]. Segundo P2, dentro das atividades, sempre haverá um elemento surpresa para ser explorado pelas crianças, seguido de suas hipóteses e, por fim, seus questionamentos: “[...] assim a gente percebeu que elas não tinham muito conhecimento dos grandes animais [...], então tudo chamava a atenção delas."

Por sua vez, P3 descreve que os planejamentos acontecem sempre no início do ano considerando-se o perfil da turma. A partir deste perfil, os aspectos avaliados são as curiosidades e os interesses das crianças. Conforme P3, como o projeto da sua turma surgiu da curiosidade sobre o livro "O ovo", seria possível trabalhar tanto a investigação, as habilidades de pensamentos, quanto às diversas linguagens.

Finalmente, P4 menciona que os planejamentos acontecem através de observações das crianças. Essas levam em consideração as atitudes, os interesses e as necessidades que a turma possui. De acordo com a professora, como o projeto da sua turma surgiu da curiosidade acerca de um texto sobre o desmatamento, as professoras começaram a planejar momentos para a ampliação do repertório sobre a sustentabilidade.

Conforme a criança vai sendo inserida nas questões relacionadas aos saberes da natureza, vai reconstruindo distintas noções que promovem mudanças no seu modo de compreender o mundo (ARCE; SILVA; VAROTTO, 2011; HARLAN; RIVKIN, 2002; BORGES; MORAES, 1998). Portanto, vão percebendo, gradativamente, relações causais, desenvolvem capacidades integradas à identificação das propriedades dos elementos vivos e não vivos, além de iniciarem a compreensão dos processos de transformação que acontecem no mundo natural. Evidentemente, isso pode acontecer a partir do emprego de diferentes linguagens (conversa, desenho, canto, modelização, para mencionar algumas que foram aludidas pelas professoras). Deste modo, vão incorporando diferentes conceitos que representam o mundo e, com eles, explicitam sentimentos, desejos e conhecimentos sobre as coisas que hipotetizam, observam e vivem. (BRASIL, 2010; 1998)

Segundo as professoras, a consideração de aspectos como a curiosidade e o interesse das crianças trata-se de um importante ponto de partida para o planejamento das atividades. Retomamos Vigotski (2004, p. 112) que aborda esta questão da seguinte forma:

[...] antes de querermos atrair a criança para alguma atividade precisamos interessála por essa atividade, ter a preocupação de descobrir se esta está preparada para tal coisa, se todas as suas potencialidades estão mobilizadas para desenvolvê-la e se a própria criança vai agir restando ao professor apenas orientar-lhe a atividade.

Ratificamos que o contentamento de uma descoberta a respeito do mundo do qual as crianças fazem parte, originam importantes contribuições, tanto no que diz respeito aos aspectos afetivos, como os relacionados aos aspectos cognitivos (VIGOTSKI, 2009). Destarte, as aprendizagens a partir de atividades que incluam as crianças no ambiente da natureza integram aspectos emocionais que necessitam ser estimulados, com a finalidade de 
gerar o desejo em conhecer, condição psicológica fundamental para a construção de um significado permanente (VIGOTSKI, 2009).

Neste sentido, apoiados nas Diretrizes Curriculares (BRASIL, 2010) argumentamos que é necessário repensar a forma como os saberes da natureza são mostrados às crianças e, por conseguinte, a maneira como esses saberes vão sendo construídos. Saberes fora de contextos devem ser problematizados, uma vez que precisam estar circunscritos à realidade sociocultural, ao nível experiencial bem como corresponder ao interesse das crianças. (VIGOTSKI, 2009; 2000)

Inferimos que, a partir das respostas apresentadas pelas professoras, bem como a observação e análise dos resultados destas propostas, concretizadas nas diferentes produções e organizadas no "Livro da Vida", conhecem determinantes psicológicas e sociais a respeito de como as crianças aprendem e se desenvolvem. Ou seja, de como incorporam as diferentes linguagens que caracterizam o mundo da cultura, portanto, de como se constituem como indivíduos (VIGOTSKI, 2004). Isto foi possível perceber por intermédio de dizeres como "a criança é que sempre vai trazer para gente o que elas querem pesquisar" e quando afirmam que sempre haverá um elemento surpresa para ser explorado, seguido de seus questionamentos e, por fim das suas hipóteses.

Ressaltamos, também, que o processo de aprendizagem está intimamente associado às questões relacionadas a sentimentos como afetividade, curiosidade, desejo, questões que seguem à frente dos aspectos cognitivos. A satisfação causada pela descoberta traz contribuições expressivas, tanto para a dimensão afetiva, como para a cognitiva (ARCE; SILVA; VAROTTO, 2011). Portanto, as aprendizagens conquistadas a partir das atividades que aconteceram ao redor dos conceitos tartaruga e jacaré, provavelmente envolveram aspectos emocionais que, ao serem estimulados, promoveram o desejo das crianças em conhecer mais, condição psicológica que favorece a construção de significados permanentes. A respeito desta questão, Vigotski (2004, p. 115) assim se manifesta:

[...] para que o objeto nos interesse, ele deve estar vinculado a alguma coisa do nosso interesse, algo já conhecido, e ao mesmo tempo deve conter algumas formas novas de atividade, senão continuará sem dar resultados [...]. Logo, para colocar esse objeto ou fenômeno em relações pessoais com o aluno, é necessário tornar o seu estudo assunto pessoal do aluno, então poderemos estar certos do êxito.

Vigotski (2004) destaca a relação estabelecida pelo professor entre os saberes e as crianças que estão aprendendo, portanto, sobre este professor incide um novo e fundamental papel: o de organizador do meio social, que é o mais importante fator educativo.

\subsection{LINGUAGENS DESENVOLVIDAS POR INTERMÉDIO DAS ATIVIDADES QUE ENVOLVEM OS SABERES DA NATUREZA}

Conforme as Diretrizes Curriculares (BRASIL, 2010) a criança trata-se de um sujeito de direitos, historicamente situada e que, nas interações, relações e práticas cotidianas vivencia, constrói sua identidade pessoal e coletiva, inserindo-se na cultura. Neste sentido, um CEI se 
constitui num importante cenário de convívio social e cultural. Decorrente desta circunstância entendemos que a proposta pedagógica pode contemplar:

[...] à criança o acesso a processos de apropriação, renovação e articulação de conhecimentos e aprendizagens por intermédio das diferentes linguagens, assim como o direito à proteção, à saúde, à liberdade, à confiança, ao respeito, à dignidade, à brincadeira, à convivência e à interação com outras crianças. (BRASIL, 2010, p. 18)

De acordo com o Referencial Curricular Nacional para a Educação Infantil (BRASIL, 1998), entre as linguagens mais comuns utilizadas na educação infantil, identificamos a linguagem oral, os desenhos, as artes visuais, a música, a escrita, a linguagem corporal, entre outras. Conforme o documento "quanto menores forem as crianças, mais suas representações e noções sobre o mundo estão associadas diretamente aos objetos concretos da realidade conhecida, observada, sentida e vivenciada". (BRASIL, 1998, p. 169)

A partir das interações das crianças com os saberes da natureza, os professores podem viabilizar significativos processos construtivos, uma vez que o contato direto com os elementos da natureza, bem como com as linguagens associadas são importantes para o seu processo de aprendizagem e desenvolvimento. (VIGOTSKI, 2000; 1994)

Conforme a aprendizagem ocorre, as crianças vão incorporando distintas formas culturais de representar o mundo (e de compreendê-lo). A apropriação das linguagens por parte das crianças exerce influências sobre o seu desenvolvimento. Entendemos que a educação infantil pode garantir experiências que "favoreçam a imersão das crianças nas diferentes linguagens e o progressivo domínio por elas de vários gêneros e formas de expressão: gestual, verbal, plástica, dramática e musical”. (BRASIL, 2010, p. 25)

A respeito das linguagens utilizadas, P1 cita que são trabalhadas a partir dos projetos, bem como no dia-a-dia. Argumenta que todas estão bastante "entrelaçadas dentro das atividades" [entrevista], entretanto a linguagem que acaba ficando mais evidente parece ser a linguagem das artes plásticas. De acordo com P1 [entrevista]: "[...] acho que [...] dentro de um projeto, a gente dá conta de muitas linguagens, que no individual, a gente não daria [...]." P1 apresenta exemplos de linguagens, além da verbal: a linguagem simbólica (na utilização de jogos de memória com base em obras de artes de Telomar Florêncio, artista plástico catarinense), a fotografia (com base nas obras do artista Charles Steuck, fotógrafo e artista plástico blumenauense), a linguagem das artes plásticas (com a criação de telas a partir de elementos da natureza, como a construção da tinta natural). P1 menciona a utilização da linguagem na atividade em ambiente natural [entrevista]:

“[...] Mesma coisa com o contato com a natureza, com essa relação que eles têm com a natureza, não acontece só dentro do projeto, acontece nas brincadeiras, acontece nas interações. Às vezes a gente opta em fazer uma interação lá em cima, no bosque, com outra turma. Então, tudo isso é uma interação para eles e a gente também está trabalhando as linguagens também dentro disso."

P2 menciona linguagens como o jogo simbólico, trabalhado em atividades como a reprodução de sons dos animais. Utiliza, também, a linguagem cinematográfica, por intermédio da exibição de documentários, além da linguagem literária, com o emprego de 
livros e blocos de histórias. Também menciona a linguagem oral e destaca a sua estimulação nesta faixa etária (P2 trabalha com crianças entre um a dois anos).

Segundo P3 é importante fazer um levantamento do conhecimento das crianças para inserir, nas atividades, linguagens como a fotográfica, matemática, bem como a linguagem das artes plásticas. P3 esclarece que utiliza a linguagem fotográfica quando faz uma pesquisa com imagens e leitura sobre animais que colocam ovos (a professora estava desenvolvendo um projeto sobre ovo). Sobre a linguagem das artes plásticas, mencionou a criação de uma escultura de argila de uma ave, desenhos e construção de um jacaré em uma tela em base de madeira, utilizando elementos específicos.

Conforme P4, várias linguagens são desenvolvidas dentro do projeto. Menciona as atividades envolvendo a linguagem das artes plásticas (com construções de obras e esculturas, baseando-se em alguns artistas que também utilizam materiais alternativos para suas obras, como Nen Cardim, artista plástico baiano), a linguagem informativa, a musical e a matemática.

Entendemos que as professoras contemplam distintas linguagens, aspecto observado nos resultados de atividades, organizadas no "Livro da Vida". Conforme já havíamos argumentado anteriormente, a criança, ao lidar e relacionar os conceitos se desenvolve, um aspecto do seu funcionamento psicológico que permite a construção de novas compreensões e que determina mudanças no seu modo de compreender o mundo (VIGOTSKI, 2009; 2004). Nesse processo, portanto, percebem, gradativamente, relações causais, desenvolvem habilidades associadas à identificação das propriedades dos elementos naturais vivos e não vivos, além da compreensão mais apurada de processos de transformação.

As crianças, ao denominarem e representarem o mundo explicitam seus sentimentos, angústias, desejos e conhecimentos sobre as coisas que observam e vivem (BRASIL, 2010; 1998). Acrescentamos, também, o contato com outras linguagens que caracterizam a cultura, como as já mencionadas pelas professoras: imagens, vídeos, música, formas, etc. As crianças são, portanto, gradualmente introduzidas em contextos cada vez mais complexos, relacionados às percepções do mundo que as rodeia. Conforme o Referencial Curricular Nacional para a Educação Infantil (BRASIL, 1998, p. 171):

[...] as crianças vão gradativamente percebendo relações, desenvolvendo capacidades ligadas à identificação de atributos dos objetos e seres, à percepção de processos de transformação, como nas experiências com plantas, animais ou materiais. Valendo-se das diferentes linguagens (oral, desenho, canto etc.), nomeiam e representam o mundo, comunicando ao outro seus sentimentos, desejos e conhecimentos sobre o meio que observam e vivem.

A partir dos dizeres, podemos perceber que há utilização de distintas linguagens conforme o projeto central do CEI, bem como os da turma. A respeito da necessidade de se conduzir as crianças nas diversas linguagens que caracterizam a cultura, Vigotski (2000) enfatiza que o desenvolvimento psicológico de uma criança não se caracteriza somente por aquilo que ela já conhece, mas, sobretudo, pelo que ela ainda pode aprender. Trata-se, portanto, de um processo de internalização das diferentes linguagens, um aspecto do funcionamento psicológico que possibilita novos modos de perceber o mundo (e lidar nele e com ele), compreendendo-o em seu sentido mais amplo (material e social). Evidentemente, isto é possível pelo emprego da linguagem oral de natureza conceitual, mas alcança uma 
dimensão mais elaborada, por exemplo, quando outras linguagens sociais são introduzidas como a música, o desenho, a arte, conforme já havíamos aludido anteriormente. Fazendo-se uma análise de atividades com os saberes da natureza, organizadas no "Livro da Vida" e ouvindo as professoras a respeito destas atividades, percebe-se que está presente a preocupação e o cuidado em utilizar linguagens a partir de um núcleo conceitual. A seguir nos referimos a duas atividades que foram desenvolvidas por P2 e P3.

$\mathrm{P} 2$, que trabalha com crianças entre um e dois anos, organizou o desenvolvimento do tema "Animais de Estimação" a partir de uma pesquisa feita com as famílias. O objetivo central era ampliar conhecimentos que as crianças já tinham sobre os animais. Para a professora, a atividade proporcionou uma significativa ampliação do repertório conceitual a respeito dos animais. O projeto da turma ganhou mais foco a partir do momento em que as crianças puderam ter contato direto com animais. O interesse pelo tema surgiu como uma surpresa dentro da sala. Por intermédio de questionamentos, a professora foi organizando, juntamente com as crianças, um contexto conceitual necessário para suas ações posteriores. Enfatizou, portanto, os conceitos expressos pelas crianças, bem como aqueles que surgiram no decorrer das ações e também dos questionamentos, cujos resultados iam sendo posteriormente registrados no "Livro da Vida". Ressaltamos o contato das crianças com uma tartaruga real e as emoções decorrentes de poder tocá-la e senti-la.

Outra atividade, apresentada por P3, tinha como tema o jacaré, com crianças entre três e quatro anos. P3 estabeleceu como objetivo a construção de diferentes jacarés (jacaré-coroa, jacaré-do-pantanal e jacaré-de-papo-amarelo) em uma grande tela, usando a técnica de Vik Muniz, artista plástico e fotógrafo, cujas obras são feitas a partir de materiais como lixo e restos de demolição. Utilizou como materiais folha de papel A3, tela com base de madeira, objetos alternativos com algumas bases e formas geométricas específicas. Para P3, a construção exercita habilidades de pensamento, de raciocínio, além da observação, comparação e imaginação ["Livro da Vida"]. Durante o desenvolvimento da atividade, as crianças também eram incentivadas para trabalhar em grupo e ouvir a opinião dos colegas.

Em sala, a partir de imagens de jacarés, P3 desafiou as crianças a desenharem um jacaré numa folha de papel. Primeiramente, houve a ampliação do desenho em A3 e, posteriormente, a construção na tela, utilizando-se diferentes elementos. A professora observou que houve dificuldades na construção da estrutura morfológica, pois ainda não conseguiam separar a imagem do corpo humano da imagem do jacaré. Diante tal fato, foi necessário fazer algumas mediações para que fossem capazes compreender as diferenças, conforme registrado posteriormente no "Livro da Vida": "Primeiramente pedimos para "o grupo desenhar a cabeça a partir de uma fotografia. A [criança 1] observou que o formato da cabeça é diferente do ser humano e a partir de duas linhas perpendiculares começou a desenhar. A professora completa: “[...]. Também trabalhamos a linguagem matemática porque foi toda uma questão espacial... Onde fica a cabeça? O corpo fica em cima ou em baixo?"

Reiteramos que, conforme já previsto pelas Diretrizes Curriculares Nacionais (BRASIL, 2010) é importante propor experiências que contribuam para a inserção nas diferentes linguagens, com o domínio processual de diversos gêneros e formas de expressão por parte das crianças. Nas duas experiências aqui relatadas é possível identificar a utilização de linguagens como a conceitual (associada aos saberes científicos sobre o animal) e a artística, quando apresentam às crianças o artista Vik Muniz e seu estilo, convidando-as à releitura para a montagem conjunta de um jacaré. 
Evidentemente, conforme a criança aprende, avança nas etapas do seu desenvolvimento (VIGOTSKI, 2004; 2000), ou seja, ao aprenderem sobre tartarugas e jacarés em contextos que promovem a ação direta das crianças com os objetos do conhecimento e as diferentes linguagens associadas, conforme mencionado por P2 e P3, vão reconstruindo distintas noções que influenciam seus modos de compreender o mundo. Neste processo, vão percebendo, gradativamente, as relações causais, desenvolvem capacidades relacionadas à identificação das propriedades dos objetos, neste caso, seres vivos, desenvolvem a compreensão dos processos de transformação e ampliam o vocabulário conceitual. Isto acontece porque as professoras empregam e articulam distintas linguagens (a fala, o desenho, o canto, a modelização, as imagens, etc.). Portanto, as crianças aprendem, aos poucos, não somente a representar o seu mundo, como compreender que este (a cultura) é formado por muitas representações (BRASIL, 2010; 1998). Harlan e Rivkin (2002) acrescentam, também, que a afetividade envolvida trata-se de uma condição psicológica importante para o processo de aprendizagem, sobretudo à relacionada aos saberes da natureza. Importante observar que, quando lidamos com crianças pequenas, a afetividade desempenha relações inseparáveis do ato de conhecer, influenciando diretamente outros sentimentos como curiosidade, emoção, além da autoconfiança.

Enfim, defendemos o princípio de que a aprendizagem dos saberes da natureza e o processo de alfabetização científica decorrente podem acontecer desde o início, mesmo antes de a criança saber ler e escrever (ARCE; SILVA; VAROTTO, 2011). Lembramos que as crianças, muito embora ainda não dominem os códigos da escrita e leitura, sentem-se confortáveis e motivadas em lidar com outras formas de linguagem, conforme percebemos na pesquisa e também evidenciado pelas professoras. Cabe ressaltar, o seu importante papel no planejamento e no desenvolvimento de atividades que, não somente contemplaram a utilização de linguagens, como atenderam importantes características psicológicas das crianças. Entendemos que todos esses procedimentos reforçaram e contribuíram para o processo de alfabetização científica, com possíveis influências sobre aspectos como o desenvolvimento intelectual e social.

\section{CONSIDERAÇÕES FINAIS}

Nosso primeiro objetivo foi descrever como acontece o planejamento das atividades que envolvem saberes sobre a natureza, pelas professoras do CEI. A este respeito, é possível perceber que há uma manifesta intenção em desenvolver temas relacionados aos saberes da natureza como prática que contribui para a formação social, afetiva e cognitiva. Isto pode ser observado com relação aos aspectos conceituais (relacionados às aprendizagens dos saberes da natureza em seus aspectos científicos), na utilização de distintas linguagens (conforme previsto pelo projeto maior da instituição), na preocupação pela participação ativa das crianças em contextos de socialização, diálogo, respeito aos colegas e adultos, manipulação e, sobretudo, nos registros, materializados no "Livro da Vida".

Com relação ao nosso segundo objetivo, consideramos importante a ação direta das crianças sobre os objetos físicos, bem como os de ordem abstrata, como a linguagem. Podemos dizer que, no decorrer das atividades, os conceitos cotidianos das crianças são levados em consideração e, a partir destes, as ações são pensadas e executadas. Valorizamos a introdução e a participação em contextos da cultura em que distintas linguagens são experimentadas, com contribuições reais para o processo de alfabetização científica. Entre estes contextos, destacamos os saberes da natureza, a arte, a literatura. No entanto, as crianças são estimuladas a lidarem e a manifestarem suas representações pela oralidade, pelo desenho 
ou até pelas modelizações, aspecto que contribui para mantê-las interessadas, com reflexos sobre a aprendizagem conceitual mais elaborada. Portanto, os resultados alcançados apontam para a atenção recorrente das professoras sobre determinantes importantes como a aquisição de linguagens e a socialização das crianças, o contato com os elementos naturais e seus fenômenos, as perguntas, entre outros.

Recomendamos que, para se transformar um contexto educativo mais rico em possibilidades de aprendizagem e desenvolvimento é fundamental o planejamento refletido sobre as atividades que serão desenvolvidas. Este trata-se de uma etapa que contempla não somente a dimensão conceitual - o que ensinar ou a dimensão didática do processo - o como fazer, mas, sobretudo, a dimensão psicológica envolvida, ou seja, como uma criança aprende.

Portanto, a partir dos resultados obtidos pela pesquisa, apresentamos sete princípios pedagógicos, apoiados em Vigotski (2009; 2004; 2000), que consideramos essenciais para a etapa de planejamento com foco no processo de alfabetização científica:

a) Organizar uma representação dos conceitos cotidianos sobre o tema que será desenvolvido e, com eles, inseri-las em situações de ensino que permitam a atividade pessoal da criança. Conforme Vigotski (2004) já havia afirmado, toda a arte do educador deve consistir apenas em orientar e regular essa atividade.

b) É imperativo criar um contexto para o estudo, visando introduzir a criança, intelectual e afetivamente, no desenvolvimento inicial de um tema sobre os saberes da natureza. Portanto, torna-se imperativo despertar o interesse pela atividade e se esta está preparada para tal. Novamente, como diria Vigotski (2004), tornar o estudo um assunto pessoal da criança.

c) Permitir e facilitar a participação de todas as crianças nas diferentes atividades e tarefas decorrentes.

d) Estabelecer um clima de relacionamento afetivo e emocional baseado na confiança, na segurança e na aceitação mútuas, em que caibam a curiosidade (a necessidade de perguntar), a capacidade de se surpreender e o interesse pelo conhecimento em si mesmo. Dito por Vigotski (2004, p. 145): “[...] todo conhecimento deve ser antecedido de uma sensação de sede".

e) Estabelecer relações entre os novos conteúdos que são objetos de aprendizagem e os conceitos cotidianos das crianças. Isto é possível quando acontecem formas novas de atividade, caso contrário, possivelmente continuará sem dar resultados.

f) Utilizar diferentes linguagens, além da conceitual. Quanto mais a criança observa, ouve e experimenta linguagens mais ela assimila e conhece; quanto maior a quantidade de elementos da realidade de que ela dispõe em sua experiência, mais significativa e produtiva será a atividade de sua imaginação.

g) Promover a utilização e o aprofundamento autônomo dos conhecimentos que as crianças estão aprendendo. Incentivá-las para que pensem e falem com as novas ideias científicas, dando suporte ao processo de internalização. $O$ pensamento não é outra coisa senão a participação de toda a experiência anterior da criança na solução de uma tarefa corrente. 
Sobre estas e outras questões, o CEI e sua equipe têm investido em formações pontuais a partir das necessidades e o comprometimento das professoras em fazer um bom trabalho. Muito embora a pesquisa não abordasse as questões concernentes à formação docente, chamou-nos a atenção à maneira como organizam esta importante etapa do processo. Portanto, faz-se necessário trazer aqui o conceito "comunidades de aprendizagem" apresentado por Nóvoa (2009) e que caracteriza um ideal de formação construído pelos próprios professores, que parte das suas necessidades articulando temas decorrentes com a participação de referenciais oriundos de distintos segmentos da sociedade, incluindo a universidade. Sobre esta participação, no processo de formação, destacamos aquelas organizadas a partir do Programa de Extensão "Educação em Ciências para o Século XXI" que, em seu sexto ano, tem atendido CEIs e escolas em suas necessidades de formação teórico-práticas.

\section{REFERÊNCIAS}

ARCE, Alessandra; SILVA, Debora; VAROTTO, Michele. Ensinando ciências na educação infantil. Campinas: Alínea, 2011.

ASTOLFI, Jean- Pierre; PETERFALVI, Brigitte; VÉRIN, Anne. Como as crianças aprendem ciências. Lisboa: Horizontes Pedagógicos, 1998.

BAUER, Martin; GASKELL, George; ALLUM, Nicholas. Pesquisa qualitativa com texto, imagem e som: um manual prático. Petrópolis: Vozes, 2008.

BLUMENAU. Projeto Político Pedagógico do CEI XXX. Blumenau, 2007. (mimeo).

BORGES, Regina Maria Rabello; MORAES, Roque. Educação em ciências nas séries iniciais. Porto Alegre: Sagra Luzzatto, 1998.

BRASIL. SECRETARIA DE EDUCAÇÃO BÁSICA. Diretrizes Curriculares Nacionais para a Educação Infantil. Brasília: MEC/SEB, 2010.

SECRETÁRIA DE EDUCAÇÃO FUNDAMENTAL. Referencial Curricular Nacional para a Educação Infantil. 3v. Brasília: MEC/SEF, 1998.

FRANCO, Maria Laura. Análise do Conteúdo. 2 ed. Brasília: Libert Livro, 2008.

LORENZETTI, Leonir; DELIZOICOV, Demétrio. Alfabetização científica no contexto das séries iniciais. Revista Ensaio, v. 3, n. 1, p. 1-17, 2001. Disponível em: http://www.portal.fae.ufmg.br/seer/index.php/ensaio/issue/view/4. Acesso em: 10 abr. de 2013.

NÓVOA, António. O regresso dos professores. Lisboa: Educa, 2009.

HARLAN, Jean Durgin; RIVKIN, Mary. Ciências na educação infantil: uma abordagem integrada. Porto Alegre: Artmed, 2002. 
VERGARA, Sylvia Constant. Métodos de pesquisa em administração. 3. ed. São Paulo: Atlas, 2008.

VIGOTSKI, Lev Semionovich. Imaginação e criação na infância. São Paulo: Ática, 2009. Psicologia pedagógica. São Paulo: Martins Fontes, 2004.

A construção do pensamento e da linguagem. São Paulo: Martins Fontes, 2000.

A Formação social da mente. 6. ed. São Paulo: Martins Fontes, 1994. 